\title{
ARMAZENAMENTO DA CASTANHA DO PARÁ COM E SEM CASCA: EFEITO DA TEMPERATURA NA RESISTENCIA AO RANÇO ${ }^{1}$
}

\author{
M.A.A. RIBEIRO; M.A.B. REGITANO-D'ARCE; U.A. LIMA; C.E. BAGGIO \\ Departamento de Ciência e Tecnologia Agroindustrial, ESALQ/USP - C.P. 9, CEP: 13418-900 - Piracicaba,SP.
}

\begin{abstract}
RFSUMO: $O$ presente trabalho visou ao estudo do comportamento da fração lipídica de castanhas do Para em casca e descascadas, conservadas por 4 meses em sacos de papel Kraft, nas seguintes condições: ao ambiente, a $2^{\circ} \mathrm{C}$ e $-15^{\circ} \mathrm{C}$. Nas castanhas em casca, mantidas ao ambiente, a formação de peróxidos somente ocorreu a partir do $2^{\circ}$ mês, alcançando o valor de $0,16 \mathrm{meq} \mathrm{O}_{2} / \mathrm{kg}$ de 6 leo. Dentro do mesmo período, a $2^{\circ} \mathrm{C} \mathrm{e}-15^{\circ} \mathrm{C}$, isto ocorreu de forma mais lenta, chegando a $0,10 \mathrm{meq} \mathrm{O}_{2} / \mathrm{kg}$, nos dois tratamentos. As castanhas descascadas apresentaram, no inicio, $9,18 \mathrm{meq} \mathrm{O}_{2} / \mathrm{Kg}$ de índice de peróxido e $1 \mathrm{mg} \mathrm{KOH} / \mathrm{g}$ de oleo de índice de acidez. Após 4 meses ao ambiente, 0 indice de peroxido chegou a $23,3 \mathrm{meq} \mathrm{O}_{2} / \mathrm{Kg}$ e a acidez a $2 \mathrm{mg} \mathrm{KOH} / \mathrm{g}$, com redução do índice de iodo. Para as castanhas a $2^{\circ} \mathrm{C}$, os índices se mantiveram estáreis, enquanto que, para aquelas a $-15^{\circ} \mathrm{C}$, ocorreu redução no índice de peróxido, no $1^{\circ}$ mês para $7,5 \mathrm{meq} \mathrm{O}_{2} / \mathrm{Kg}$ de amostra, mantido até o final do experimento. Os índices de iodo e de acidez se mantiveram estáveis e o exame espectrofotométrico na faixa ultravioleta confirmaram estes dados. De uma maneira geral, observou-se que o abaixamento da temperatura de armazenamento contribuiu para aumentar o tempo de conservação das castanhas, que será ainda maior se forem armazenadas em casca.

Descritores: castanha do Pará, armazenamento, temperatura de armazenamento, ranço, bleo
\end{abstract}

\section{WHOLE AND SHELLED BRAZIL NUT STORAGE: EFFECT OF THE TEMPERATURE ON THEIR RESISTANCE TO RANCIDITY}

\begin{abstract}
ARSTRACT: The objective of this study on whole and shelled Brazil nuts was to determine the changes in the lipid fraction when stored for four months in ordinary paper bags, at ambient temperature, $2^{\circ} \mathrm{C}$ and $-15^{\circ} \mathrm{C}$. Whole nuts kept at room temperature had an increase in peroxide formation in the second month of storage, reaching $0.16 \mathrm{meq}$ $\mathrm{O}_{2} / \mathrm{kg}$ oil. The nuts kept at $2^{\circ} \mathrm{C}$ and $-15^{\circ} \mathrm{C}$, had a lower increase, reaching $0.10 \mathrm{meq} \mathrm{O}_{2} / \mathrm{kg}$ in both treatments, within the same period. Shelled nuts had an initial peroxide value of $9.18 \mathrm{meq} \mathrm{O}_{2} / \mathrm{kg}$ oil and $1 \mathrm{mg} \mathrm{KOH} / \mathrm{g}$ oil of acid value. After four months at room temperature, the peroxide value reached $23.3 \mathrm{meq} \mathrm{O}_{2} / \mathrm{kg}$ and acidity, $2 \mathrm{mg}$ $\mathrm{KOH} / \mathrm{g}$, with a reduction in iodine number. The nuts at $2^{\circ} \mathrm{C}$ showed minor changes. The nuts at $-15^{\circ}$ showed reduction in peroxide value to $7.5 \mathrm{meq} \mathrm{O}_{2} / \mathrm{kg}$ in the first month which was mantained until the end of the experiment. Iodine numbers and acid values were relatively stable as confirmed by spectrophotometric determinations. The conclusion is that the reduction in storage temperature contributed to the increase in time of conservation of the Brazil nuts, specially if they are not shelled.
\end{abstract}

Key Words: Brazil nut, storage, storage temperature, rancidity, oil

\section{INTRODUÇÃO}

A castanha do Pará tem reconhecido valor nutricional, decorrente de sua composição em lipídeos e proteínas. Segundo NERY (1969) as castanhas apresentam 60 a $70 \%$ de lipídeos e 15 a $20 \%$ de proteína, sendo que o óleo, apesar de comestível, ainda não é largamente comercializado.

A castanha é semente da castanheira do Pará, Bertholletia excelsa, planta da família das
Lecitidáceas, cultivada em toda a Amazônia e é considerada uma de suas maiores riquezas na região dos castanhais.

As vinte mil toneladas de castanha do Pará produzidas anualmente são quase totalmente exportadas, devido a um consumo interno de apenas $1 \%$ da produção anual.

Entre as razões para o reduzido consumo, podem estar a baixa qualidade de conservação das castanhas e a dificuldade de se quebrar a casca. 0 ranço parece ser o principal motivo da rejeição.

\footnotetext{
${ }^{1}$ Trabalho realizado com auxilio da FAPESP.
} 
ASSUNÇÃO et al. (1984) avaliaram a estabilidade do óleo bruto de castanha quanto à oxidação, em comparação com os óleos de sementes de maracujá e seringueira, todos de plantas típicas da Amazônia. O óleo de castanhas do Pará apresentou estabilidade intermediária em relação aos outros dois, atribuída ao seu alto teor em ácidos graxos insaturados $(41,2 \%$ de oléico e $36,1 \%$ de linoléico).

Segundo BILLEK (1983) a deterioração oxidativa pode provocar além das alterações organolépticas conhecidas, perda do valor nutricional e aparecimento de compostos tóxicos.

HOLLADAY et al. (1979) embalaram pecãs cruas e tostadas em atmosfera de díxido de carbono em sacos plásticos de nylon laminado e de etileno vinil acetato (EVA) e as armazenaram ao ambiente. Após 6 semanas, o aroma das pecãs "in natura" estava melhor que o das testemunhas, mantidas a $1,7^{\circ} \mathrm{C}$ e $65 \%$ de Umidade Relativa. Entretanto, ao fim de 27 semanas de armazenamento, as pecãs tostadas e não tostadas apresentaram características semelhantes às das testemunhas. Em período mais longo, todos os tratamentos foram inferiores às testemunhas.

Segundo GUADAGNI et al. (1978) o descascamento ou quebra das cascas das nozes e castanhas expõe as amêndoas ao contato direto com o ar e facilita as alterações oxidativas. Somente quando armazenadas sob atmosfera controlada de oxigênio, em temperatura de $18,5^{\circ} \mathrm{C}$ e $27^{\circ} \mathrm{C}$, permanecem aceitáveis por um tempo maior.

Segundo YOKOYA et al. (1971) as amêndoas de castanhas podem ser armazenadas com segurança em ambientes com umidade relativa inferior a $70 \%$, por um período de 8 meses, sem alterações indesejáveis. Castanhas inteiras, em casca, parcialmente desidratadas, contendo $6,8 \%$ de umidade, armazenadas em ambiente com $80 \%$ de meses. Segundo os mesmos autores (1970) as castanhas descascadas armazenadas em ambiente com umidade relativa superior a $80 \%$, em temperatura de $26^{\circ} \mathrm{C}$ a $28^{\circ} \mathrm{C}$, apresentaram crescimento fúngico em sua superfície e aumento de acidez do óleo proporcional ao crescimento dos micélios.

TAPPEL et al. (1957) mediram a absorção de oxigênio pelo óleo e por pedaços de nozes mantidos em atmosfera de oxigênio a $37^{\circ} \mathrm{C}$ e observaram que, nas primeiras 200 horas de armazenamento o b́leo apresentou um periodo de indução, no qual não houve absorção do gás, umidade relativa, podem ser conservadas por até 6

seguido de outro período em que ocorreu rápida absorção do oxigênio. Em nozes em pedaços houve imediata e gradual absorção de oxigênio até 1.000 horas, que decresceu após cerca de 1.500 horas de armazenamento. Nas nozes em pedaços, os antioxidantes naturais ofereceram pouca proteção contra a auto-oxidação, especialmente quando a película das nozes foi quebrada ou soltou-se. $\mathrm{Na}$ estocagem comercial das nozes em pedaços, a presença de oxigênio favoreceu a oxidação dos lipídeos, portanto o estabelecimento do ranço oxidativo, e a redução da qualidade.

\section{MATERIAL E MÉTODOS}

\section{Matéria-prima}

A matéria-prima constou de castanhas do Pará com casca e descascadas, quebradas em metades, tipo exportação.

O produto descascado foi adquirido em saco multifoliado aluminizado de $20 \mathrm{Kg}$ a vácuo, impermeável ao ar e à umidade. As castanhas em casca foram enviadas do castanhal para o laboratório.

\section{Instalação do experimento e execução da pesquisa}

As castanhas em casca e descascadas foram distribuidas em sacos de papel Kraft $\mathrm{c}$ armazenadas sob três diferentes condiçôes ambientais: congeladas $\left(-15^{\circ} \mathrm{C}\right)$, refrigeradas $\left(2^{\circ} \mathrm{C}\right) \mathrm{c}$ ao ambiente. Cada embalagem foi armazenada com $300 \mathrm{~g}$ de amêndoas descascadas $\mathrm{c} 600 \mathrm{~g}$ de castanhas em casca, no total de 24 sacos.

As castanhas armazenadas nos diferentes ambientes foram submetidas a análises químicas em triplicata a cada 30 dias, durante 4 meses.

No armazenamento ao ambiente, foram registradas as temperaturas mínimas e máximas diárias, no decorrer dos 4 meses, sendo:

Temperatura
Mínima

$1^{\circ}$ mês $\quad 20^{\circ} \mathrm{C}$

$2^{\circ}$ mês $\quad 18^{\circ} \mathrm{C}$

$3^{\circ}$ mês $\quad 20^{\circ} \mathrm{C}$

$4^{\circ}$ mês $\quad 22^{\circ} \mathrm{C}$

\section{Temperatura} Máxima 


\section{Métodos Analíticos}

As análises químicas foram realizadas no óleo das castanhas do Pará, obtido por prensagem a frio, através de prensa hidráulica modelo Carver, de laboratório. amêndoas.

$A$ análise de umidade foi feita nas

\section{Matéria-seca}

As amêndoas foram picadas, passadas em peneira de $3 \mathrm{~mm}$ de abertura. Em seguida, foram distribuídas $\mathrm{em}$ placas de vidro previamente taradas, pesadas e colocadas para secar em estufa a $105^{\circ} \mathrm{C} \pm 1^{\circ} \mathrm{C}$, por uma noite, repetidas vezes, até peso constante (INSTITUTO ADOLFO LUTZ, 1985).

\section{Índice de Acidez}

Determinação feita conforme o método oficial da STAZIONE SPERIMENTALE PER LE INDUSTRIE OLI E DEI GRASSI, NGD C-10 (S.S.O.G., 1976).

\section{Índice de Peróxido}

Determinação feita pelo método NGD C-35 (S.S.O.G., 1976).

\section{Indice de Iodo}

Determinação feita pelo método de Wijs NGD C-32 (S.S.O.G., 1976).

Exame espectrofotométrico sob luz ultravioleta

Determinado conforme a NGD C-40 (S.S.O.G., 1976) em 232 e $270 \mathrm{~nm}$.

\section{Análise Estatística}

Os dados obtidos foram analisados através do esquema de análise de variância com aplicação dos testes de Tukey através do programa SANEST - Sistema de Análise Estatística para Microcomputadores, para as variáveis grau de umidade, índice de acidez, peróxido, iodo e exame espectrofotométrico na faixa do ultravioleta de $232 \mathrm{~nm}$ e $270 \mathrm{~nm}$.

\section{RESULTADOS E DISCUSSÃO}

A Figura 1 apresenta os valores de grau de umidade das castanhas com e sem casca, durante o período de estudo, nas três diferentes condições de armazenamento.

Quando armazenadas ao ambiente, ambas as castanhas do Pará com e sem casca apresentaram o maior valor de umidade ao cabo dos quatro meses (ca. $4,5 \%$ ), podendo-se admitir que tenham atingido o equilibrio higroscópico apesar de apresentarem níveis de umidade iniciais diferentes.

$\mathrm{O}$ armazenamento a $2^{\circ} \mathrm{C}$ foi o que menos permitiu absorção de umidade mantendo níveis próximos aos iniciais para cada tipo de castanha. As castanhas congeladas e refrigeradas, com e sem casca, atingiram o $4^{\circ}$ mês com valores bem próximos, $4,0 \%$ e $3,0 \%$, respectivamente.

As castanhas descascadas estavam embaladas em sacos aluminizados a vácuo e com a umidade controlada pelas condições próprias da embalagem. Com a retirada desse meio e, armazenadas nas condições do estudo, as castanhas se comportaram de acordo com a influência que cada ambiente proporcionou.

Apesar das oscilações ocorridas, através da análise estatística, o grau de umidade das castanhas em casca e descascadas não diferiu significativamente entre os tratamentos, no período de quatro meses.

$O$ índice de acidez das castanhas em casca a $2^{\circ} \mathrm{C} \mathrm{e}-15^{\circ} \mathrm{C}$ manteve-se sempre próximo ao inicial $(0,13 \mathrm{mg} \mathrm{KOH} / \mathrm{g}$ oleo) durante os primeiros meses de armazenamento, aumentando somente após 3 ou 4 meses (Figura 2). Ao ambiente, estas castanhas apresentaram triplicada a acidez já no $1^{\circ}$ mês. A baixa temperatura pode ter impedido um rápido aumento na acidez do produto, apesar de a análise estatística revelar que não houve diferença significativa entre os tratamentos, nos quatro meses.

O indice de acidez do óleo das castanhas descascadas indicou um produto com acidez, apesar de baixa, quase dez vezes maior do que as em casca, como pode ser visto na Figura 2. Este foi mantido somente pelas castanhas armazenadas a $-15^{\circ} \mathrm{C}$. A ação da refrigeração se mostrou tão menos eficiente em impedir a formação de ácidos graxos livres quanto a exposição ao ambiente, proporcionando um óleo com acidez crescente, que ao final de quatro meses foi o dobro da inicial para a castanha mantida ao ambiente. 


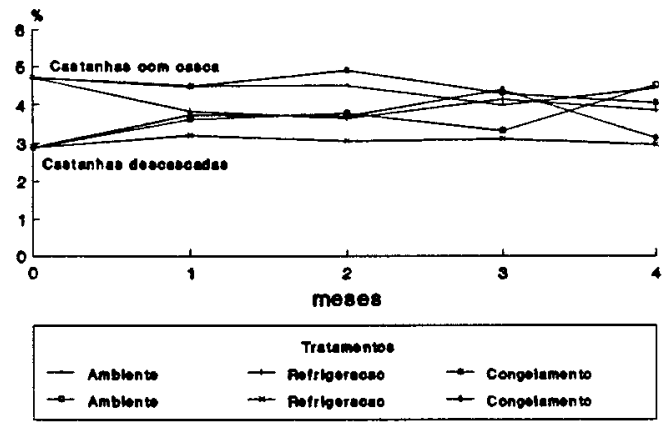

Figura 1. Umidade das castanhas do Para armazenadas

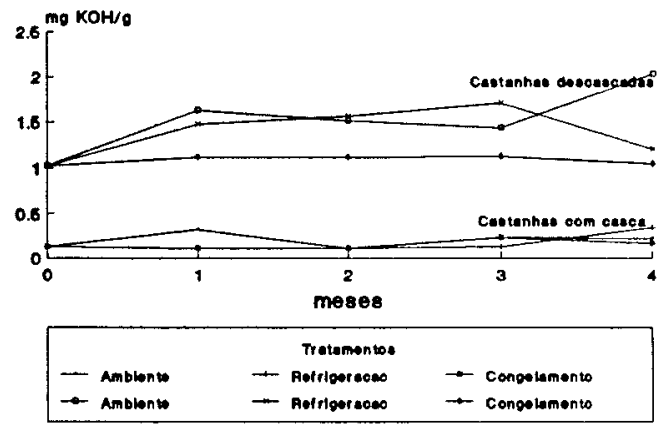

Figura 2. Indice de acidez do oleo das castanhas do Para

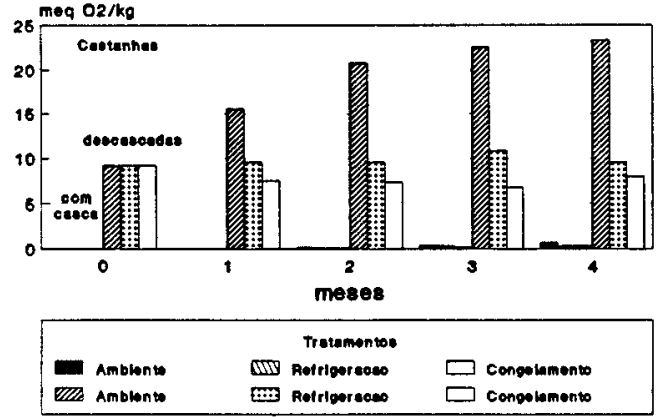

Figura 3. Indice de peroxido dos oleos das castanhas do Para

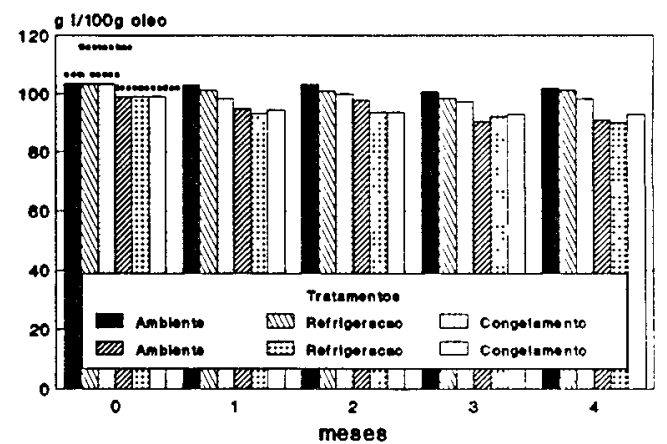

Figura 4. Indice de lodo dos oleos das castanhas do Para

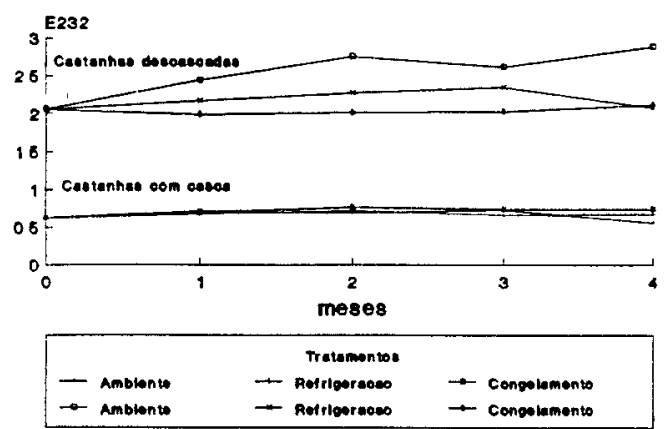

Figura 5. E232 dos oleos das castanhas do Para

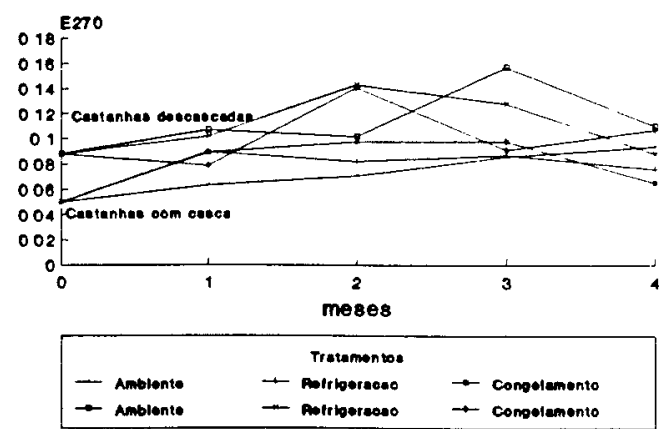

Figura 6. E270 dos oleos das castanhas do Para 
Apesar das diferenças nos resultados, a análise estatística, para cada tipo de castanha, revelou que os tratamentos não diferiram entre si no período de estudo.

A Figura 3, contendo os resultados dos índices de peróxido, revela que a castanha em casca estava isenta de compostos oxidados no início do experimento. Durante o período de armazenamento, a formação de peróxidos foi pequena, variando com valores próximos aos iniciais, sendo que as castanhas ao ambiente apresentaram os maiores valores $\left(0,75 \mathrm{meq} \mathrm{O}_{2} / \mathrm{kg}\right.$ oleo). Quando mantidas a baixas temperaturas, a reação oxidativa parece ter sido reduzida à metade devido à ação benéfica da presença da casca aliada ao frio. GUADAGNI et al. (1978) também já haviam verificado a efetiva ação protetora da casca.

A análise estatística não detectou diferença significativa entre os tratamentos a nível de $1 \%$.

Já para as castanhas descascadas, cujos dados também estão apresentados na mesma Figura 3, ocorreu rápida formação de compostos primários (peróxidos) de ranço nas castanhas mantidas ao ambiente. Para as castanhas refrigeradas e congeladas, os índices se apresentaram muito próximo dos iniciais, evidenciando a eficiência dos tratamentos, com vantagem para o congelamento, em que esse valor diminuiu para abaixo do inicial. Estas observações vem complementar as de GUADAGNI et al. (1978) demonstrando que a temperatura mais baixa preservou amêndoas sem 0 recurso de atmosfera modificada.

De acordo com a análise estatística, a partir do $2^{\circ}$ mês, as castanhas descascadas refrigeradas e congeladas, diferiram significativamente das mantidas ao ambiente.

Os resultados de índice de iodo apresentados na Figura 4 indicam que não ocorreram profundas alterações na cadeia dos ácidos graxos, porém houve gradativa diminuição. Todos os valores mantiveram-se relativamente estáveis ao fim de quatro meses, apesar de que as castanhas descascadas apresentaram valores menores $(99,13$ $\mathrm{mg} \mathrm{l} / 100 \mathrm{mg}$ óleo) desde o início, visto apresentar o óleo já em processo de deterioração oxidativa, com índice de peróxido 9,18 , conforme mostra a Figura 3. Isto era esperado de certa forma devido ao pré-processamento a que as castanhas foram expostas, incluindo classificação, secagem, quebra manual, etc. Quanto maior a manipulação, maior a exposição ao oxigênio, ao calor e à injúria física, fatores que favorecem o ranço. Dentro de cada tipo de castanha não houve diferenças significativas. As maiores reduções foram encontradas para as congeladas em ambos os tipos de castanha.

Para as castanhas com casca, a pequena ou nula presença de compostos peróxidos, mais o alto índice de iodo $(103,39 \mathrm{mg} 1 / 100 \mathrm{mg}$ b́leo), levou os dados de absorção na faixa do ultravioleta de 232 e 270nm (Figuras 5 e 6) a apresentaram oscilações, porém, sempre com valores muito próximos do ocorrido no início da estocagem (E232 0.555 a 0,765 e E270 0,050 a 0,098).

Estes valores demonstraram que, sendo as reações de oxidação muito lentas, é impossível evidenciar qual a predominante $e$, que, somente após um período maior de armazenamento, os compostos formados poderiam ser medidos e distinguidas as etapas da reação de instalação do processo de ranço.

A análise estatística mais uma vez não detectou diferenca entre os valores dos diferentes tratamentos, nos meses de armazenamento, com exceção apenas do $4^{\circ}$ mês, para as castanhas com casca.

A presença de compostos menores (E270) foi maior nos óleos de castanhas descascadas mantidas ao ambiente, comparadas às mantidas sob baixas temperaturas, concordando com o comportamento apresentado pelo índice de peróxido, pois com o aumento da conjugação de dienos medido em $232 \mathrm{~nm}$, aumenta proporcionalmente a absorção de oxigênio com a subsequente formação de peróxido nos estágios iniciais da oxidação (ROBERTSON et al., 1973). O valor em $232 \mathrm{~nm}$ para o b́leo das castanhas descascadas congeladas apresentou-se estável no período de quatro meses, enquanto que ocorreram pequenas elevações nos três primeiros meses para as castanhas refrigeradas.

Os resultados de absorção em $270 \mathrm{~nm}$ (Figura 6) confirmaram o estado mais avançado de oxidação das castanhas descascadas. Nos tres tratamentos, a reação primária da oxidação foi mais intensa nas castanhas ao ambiente enquanto que a baixa temperatura permitiu maior estabilidade para o produto descascado (Figura 3), reduzindo o seu valor de peróxidos (com a quebra dos peróxidos a compostos menores) e aumentando o valor de E270.

\section{CONCLUSÕES}

- A casca das castanhas mostrou-se um eficiente meio de conservação, protegendo as amêndoas dos agentes oxidantes, permitindo a manutenção da sua 
qualidade sem maiores alterações, durante o período do experimento.

- $O$ abaixamento da temperatura de armazenamento contribuiu para a manutenção da qualidade das castanhas em casca e descascadas por, pelo menos, 4 meses.

\section{REFERÊNCIAS BIBLIOGRÁFICAS}

ASSUNÇÃO,F.P.; BENTES, M.H.S.; SERRYA, H. A comparison of stability of oils from Brazil nut, from rubber and passion fruit seeds. Journal of the American Oil Chemists' Society, Champaign, v.61, n.6, p.1031-1036, 1984.

BILLEK, G. Lipid stability and deterioration. In: PERKINS, C.J. \& VISEK, W.J. Dietary Fats \& Health, Champaign, A.O.C.S., 1983.

GUADAGNI, D.G.; SODERSTROM, E.L. \& STOREY, C.L. Effects of controlled atmosphere on flavor stability of almonds. Journal of Food Science, Chicago, v.43, n.4, p.1077-1080, 1978.

HOLLADAY, C.E.; PEARSON, J.L. \& SLAY, W.O. A new packaging method for peanuts and pecans. Journal of the Food Science, Chicago, v.44, n.5, p.1530-1533, 1979.

INSTITUTO ADOLFO LUTZ Normas Analíticas, v.1. Métodos químicos e físicos para análise de alimentos. $3^{2}$ ed. São Paulo, IAL, 1985. p.21.

NERY, J.P. Castanha-do-Pará. Boletim do Instituto de Tecnologia de Alimentos, Campinas, v.20, p.13-25, 1969.
ROBERTSON, J.A.; MORRISON, W.H. \& BURDICK, D. Chemical evaluation of oil from field and storage-damaged soybeans. Journal of the American Oil Chemists' Society, Champaign, v.50, n.11, p.443-445, 1973.

STAZIONE SPERIMENTALE PER LE INDUSTRIE DEGLI OLI E DEI GRASSI (S.S.O.G.) - Comissione Tecnica Per Le Industrie Degli Oli Vegetali, Grassi Vegetali, ed Animali, delle Proteine Vegetali, degli Oli Minerali, dei Colori e Vernici, dei Detergenti e Tensoattivi, dei Prodotti Cosmetic e dei Igiene Personale. Norma Italiane per il Controllo dei Grassi e Derivati, Milano, 1976.

TAPPEL, A.L.; KNAPP, F.W. \& URS, K. Oxidative rancity in food products. II - Walnuts and other nuts meats. Food Research, Champaign, v.22, p.287-298, 1957.

YOKOYA, F; ANTUNES, A.J. \& JORDĀO, B.A. Deterioração de castanha do Pará: I - Armazenamento das amêndoas. Revista Brasileira de Tecnologia. São Paulo, v.1, n.1, p.17-21, 1970.

YOKOYA, F; ANTUNES, A.J. \& JORDĀO, B.A. Deterioração de castanha do Pará: II-Arma/cnamento das castanhas. Revista Brasileira de Tecnologia, São Paulo, v.2, n.3, p.117-120, 1971.

Enviado para publicaçāo em 10.03 .93

Aceito para publicação em 16.07 .93 